\title{
A PROBABILISTIC ANALYSIS OF SURFACE WATER FLOOD RISK IN LONDON
}

\author{
Katie Jenkins ${ }^{1, *}$, Jim Hall ${ }^{1}$, Vassilis Glenis ${ }^{2}$, Chris Kilsby ${ }^{2}$ \\ ${ }^{1}$ Environmental Change Institute (ECI), School of Geography and the Environment, \\ University of Oxford, UK \\ ${ }^{2}$ School of Civil Engineering and Geosciences, Newcastle University, UK
}

* Corresponding author: Environmental Change Institute (ECI), School of Geography and the Environment, University of Oxford, Oxford OX1 3QY, UK; e-mail: katie.jenkins@eci.ox.ac.uk 


\section{ABSTRACT}

Flooding in urban areas during heavy rainfall, often characterised by short duration and high intensity events, is known as 'surface water flooding'. Analysing surface water flood risk is complex as it requires understanding of biophysical and human factors, such as the localised scale and nature of heavy precipitation events, characteristics of the urban area affected (including detailed topography and drainage networks), and the spatial distribution of economic and social vulnerability. Climate change is recognised as having the potential to enhance the intensity and frequency of heavy rainfall events. This study develops a methodology to link high spatial resolution probabilistic projections of hourly precipitation with detailed surface water flood depth maps and characterisation of urban vulnerability, to estimate surface water flood risk. It incorporates probabilistic information on the range of uncertainties in future precipitation in a changing climate. The method is applied to a case study of Greater London and highlights that both the frequency and spatial extent of surface water flood events are set to increase under future climate change. The Expected Annual Damage (EAD) from surface water flooding is estimated to be to be $£ 171$ million, $£ 343$ million and $£ 390$ million/year under the baseline, 2030 high and 2050 high climate change scenarios respectively.

\section{KEYWORDS}

surface water flood risk; economic damage; climate change 


\section{INTRODUCTION}

Flooding (including coastal, riverine, and flash flooding) is one of the most frequent and damaging natural disasters in terms of number of people affected and economic damage ${ }^{(1)}$. As such, effective long-term flood risk management is an increasingly critical issue for many governments around the world ${ }^{(2)}$.

Flooding in urban areas during heavy rainfall is known as surface water flooding, pluvial flooding $^{2}$ or storm water flooding ${ }^{(3,4)}$. Surface water flooding occurs due to a complex interplay of factors, including the precise location, intensity and duration of rainfall, the characteristics of urban land surfaces and the engineering design of the surface drainage and sewer system. Surface water flooding tends to be most severe during intense rainfall downpours, which are often, but not exclusively, associated with convective rainfall events. Rainfall may be infiltrated into the ground, but in urban areas with impermeable surfaces rainfall will flow on the surface in directions modified by the form of buildings and streets and will accumulate at locations with low topographical elevation. These processes are modified by drains that are designed to convey water away from urban areas on the surface or in pipes ${ }^{(5)}$.

The scale and severity of economic impacts will be dependent on the characteristics of the event, the vulnerability of the area and population exposed to the event ${ }^{(6)}$ and, where in place, the effectiveness of adaptation options. These can include options to increase pervious surfaces, property level protection measures (PLPMs) that prevent water from entering buildings or reduce the costs of repair following a flood, or investments in drainage systems.

${ }^{1}$ Pluvial flooding can be defined as flooding resulting from heavy rainfall which does not infiltrate the ground but ponds or flows overland before the runoff enters a natural or man-made drainage system or watercourse, or where water cannot enter a system as it is already at full capacity. Pluvial flooding is often characterised by short duration high intensity rainfall events (typically over $20 \mathrm{~mm} / \mathrm{h})^{(2)}$. 
In England, the consequences of surface water flooding were brought to the forefront by the summer floods of $2007^{(7)}$, which differed in scale and type from recent floods in that a much higher proportion of flooding than normal came from surface water flooding rather than rivers or the sea ${ }^{(8)}$. The Pitt Review ${ }^{(7)}$, conducted to provide lessons and recommendations in the aftermath of the floods, highlighted major gaps in the understanding and management of risks from surface water flooding in the UK compared to fluvial or tidal flooding. This has been further stressed following heavy rainfall in December 2015 and January 2016 with initial damages estimated in the range of $£ 5$ to $£ 5.8$ billion ${ }^{(9)}$. Similar concerns have also been raised across Europe with some member states in the past giving a much lower priority to this type of flood risk meaning that vulnerability has crept upwards ${ }^{(4)}$.

The need for further attention to this type of risk in the UK is also apparent given that the National Risk Register lists surface water flooding as the most likely cause of damage to properties, with estimated annual costs of $£ 1$.3bn to $£ 2.2 \mathrm{bn}{ }^{(10)}$. These concerns are made more pressing by the influence of climate change on the projected frequency and intensity of rainfall events in the UK ${ }^{(11,12)}$, expected to result in an increase in surface water flood events ${ }^{(13)}$. Combined with an increasing pattern of urbanisation Defra estimated that damages from surface water flooding could increase by $60-220 \%$ over the next 50 years ${ }^{(14)}$.

It is, however, extremely challenging to predict the occurrence and extent of surface water flood events, limiting the ability to warn and plan for future risks ${ }^{(15)}$. Similarly, there has been less emphasis on conducting quantitative assessments of economic costs of surface water flooding for the present day and under future climate change, which could then be used to evaluate, support and prioritise decision making in a more standardised manner ${ }^{(2)}$. As such, motivation and implementation of adaptation policy responses is inhibited by inadequate quantification and provision of risk based information. 
This study contributes to this area through the development of a surface water flood risk analysis methodology. Detailed surface water flood depth maps for Greater London have been generated but represent the modelled effect of a uniform rainfall event across the whole area, while in reality rainfall events, and subsequent impacts, will be spatially heterogeneous. Using an hourly Weather Generator (WG), conditioned upon the UK's probabilistic climate projections (UKCP09), flood events are modelled. We then rescale the surface water flood depth maps for each simulated flood event to generate corresponding spatial flood outlines, which are combined with economic vulnerability data. The large simulation of rainfall events enables the quantification of flood risk, both for the present and future, whilst the probabilistic climate projections are beneficial to enable quantification of some of the climate model uncertainties.

The case study area is introduced in Section 2. Section 3 provides an overview of the integrated modelling framework and the model components and methodology in detail. Results are presented and discussed in parallel in section 4 and conclusions presented in Section 5.

\section{STUDY AREA}

The analysis focuses on a case study of surface water flood risk in Greater London (Fig.1), encompassing an area of $1,574 \mathrm{~km}^{2}$, a population of approximately 7.5 million people, and 3.3 million residential dwellings ${ }^{(16)}$. 


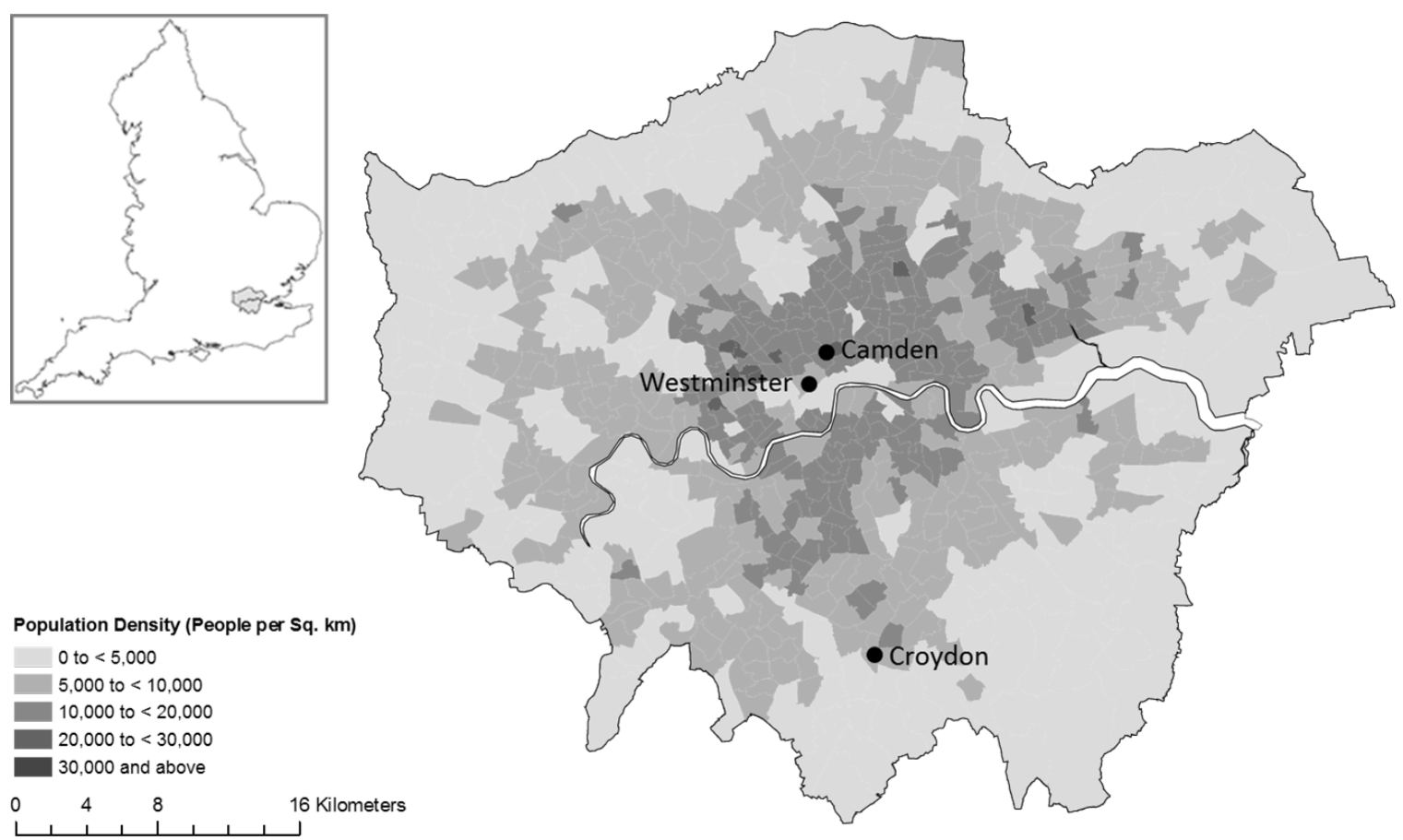

Fig. 1: The boundary of the Greater London study, 2015 population density ${ }^{(17)}$ area, and location in England (inset)

Surface water flooding is considered to be the most likely cause of flood events, and one of the greatest short-term climate risks to Greater London ${ }^{(18,19)}$. It is estimated that up to 680,000 properties in London are at risk from surface water flooding with a probability of at least 0.5 per cent in a year (i.e. a 1/200 year return period event), and that 400,000 of these are additional to those properties vulnerable to rivers and the sea ${ }^{(20)}$. The number of residential properties prone to surface water flooding has been increasing from 2001 to 2011, as has the proportion of urban land covered with manmade surfaces (>70\% in many London boroughs) ${ }^{(21)}$.

Because of the scarcity of undeveloped land which is not otherwise protected for recreational or environmental purposes, over $96 \%$ of new developments in London in recent years have been on brownfield sites. However, many of the remaining brownfield sites for development are in 
flood risk zones ${ }^{(19)}$. Developments in areas prone to surface water flooding have been increasing by 0.5 to $0.7 \%$ per year from $2008^{(14)}$. These issues highlight how the current landuse and development plans may increase the exposure to surface water flood risk in Greater London. Furthermore, as large parts of London's sewer system (which combines storm water drainage with waste water sewerage) date back to the nineteenth century, increased population and reduced urban surface permeability mean that the city's drainage systems are under acute pressure.

\section{MODELLING FRAMEWORK}

The modelling framework reflects the scale and characteristics of urban surface water flood risk, the purpose of the assessment, and availability of data. Meso-scale assessments, such as this, have been shown to be useful for regional flood risk mapping and management, as well as exploring future scenarios of climate change ${ }^{(2)}$. An overview of the model framework is illustrated in Fig. 2 (and described in sections 3.1 - 3.4). 


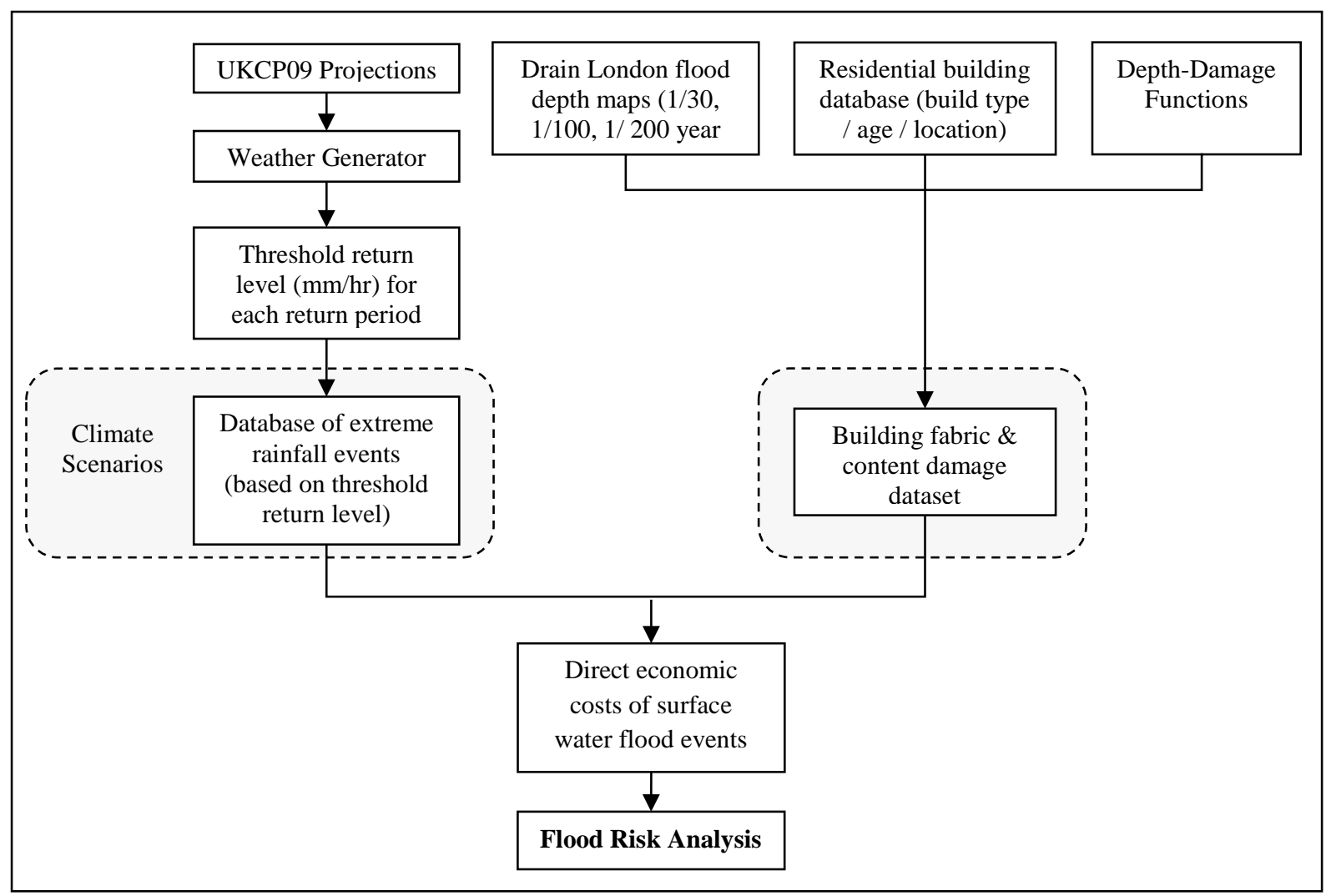

Fig. 2: Overview of the risk based modelling framework

In summary, the method uses detailed surface water flood depth maps for $1 / 30,1 / 100$, and $1 / 200$ year return periods. Direct damages are estimated by overlaying these surface water flood maps onto GIS data of residential buildings, with potential economic damage to building fabric and contents calculated using flood depth-damage functions ${ }^{(22)}$. Non-residential properties are not considered because of concerns about the accuracy of geospatial data for these properties.

To identify the occurrence and spatial extent of individual flood events the corresponding return level of extreme precipitation events of $1 / 30,1 / 100$, and 1/200 year return periods are estimated for the baseline period (1961-1990), using hourly rainfall data from a spatial version of the UKCP09 Weather Generator (WG). The rainfall return levels are then used as thresholds to 
investigate the possible change in frequency of rainfall events of given magnitude under future climate scenarios. This frequency analysis facilitates a probabilistic analysis of extreme rainfall events, as well as providing an assessment of underlying climate model uncertainties. Thus, for each rainfall event identified the spatial extent can be mapped, potential flood depth ascertained from the corresponding surface water flood depth map, and economic damage to residential buildings estimated using depth-damage functions.

\subsection{Spatial Weather Generator for Urban Areas}

The spatial and temporal scale of climate model outputs, even from dynamically downscaled regional climate models, is often inconsistent with that required for climate change impact studies. This is a particular problem for surface water flood risk assessments because the severity of flooding is influenced by local variation in rainfall conditions. Stochastic Weather Generators (WG) have proved beneficial for flood risk analysis, including risk to urban infrastructure, as they can provide synthetic weather records to extrapolate short time series or fill gaps where data is not available (e.g. providing larger samples of flood events for analysis $\left.{ }^{(23)}\right)$, as well as for downscaling climate change scenarios in both space and time ${ }^{(24,25)}$. They are less computationally expensive compared to climate models, can provide multiple realisations for the same climate projection, and may be just as good or better than climate models when representing weather variability and extremes ${ }^{(26)}$.

The most recent UK climate scenarios (UKCP09) were accompanied by a stochastic WG which can provide daily and hourly time series of weather variables for present and future conditions at a $5 \times 5 \mathrm{~km}$ grid square resolution ${ }^{(27)}$. The WG incorporates a stochastic rainfall model, which simulates future rainfall sequences, and then generates other weather variables according firstly to the rainfall state and then to other inter-variable relationships which are represented as 
regression relationships. The WG has been well validated against observed data from 1961 to $1990^{(28)}$.

The UKCP09 scenarios were novel in their representation of climate model uncertainties, based on the range of climate model responses from a large perturbed physics ensemble ${ }^{(29)}$. Results are presented as probability distributions of projected changes which can be used to parameterise changes in the WG. This is achieved by providing a Monte Carlo sample of 10,000 equiprobable vectors of change factors, sampled from the full range of the UKCP09 probability distribution, to perturb the statistics of the WG. The approach relies on deriving monthly factors of change for various statistics from control to future scenarios, and applying these to observed statistics (described in ${ }^{(27)}$ ). This method is preferred to using the Regional Climate Models rainfall climatology directly, as studies have illustrated this does not reproduce the spatial patterns of mean rainfall or seasonality, nor represent extreme dry spells or extreme rainfall events, accurately ${ }^{(30,31)}$. This leads to a two-level sampling scheme in which (i) repeated representations of the WG for a given vector of input parameters can be used to explore the effects of natural variability and (ii) sampling different vectors of change factors explores the effect of climate model uncertainty in projected future impacts. In the results reported here we refer to climate projections explored via (ii).

However, the UKCP09 WG simulates weather sequences at a single site so does not provide spatial consistency in time across neighbouring grid cells ${ }^{(27)}$. The lack of spatial coherence limits the use of the WG for analysing aggregate impacts over several grid cells. In this study a modified version of the UKCP09 WG is used which provides spatially coherent time series data (described in $(24,25)$. 
Hourly precipitation time-series data for 30 year stationary sequences are taken from the WG for each grid cell in the study area. These series are generated 100 times each, with each run based on a different randomly sampled vector of change factors, to allow probabilistic analysis. Data are generated for the baseline period (1961-1990) and for the 2030s and 2050s under high $(\mathrm{H})$ emission scenarios. These future scenarios are equivalent to the IPCC SRES B1 and A1FI scenarios and comparable to the latest generation IPCC Representative Concentration Pathways 4.5 (medium emissions) and 8.5 (high emissions) respectively ${ }^{(32)}$.

In order to assess surface water flood risk the return level of extreme precipitation events for $1 / 30,1 / 100$, and $1 / 200$ year return periods are estimated from the baseline data. To calculate the recurrence interval the hourly annual maximum series (AMS) is derived from the $100 * 30$ year precipitation times-series data for each grid cell. This approach has been widely used and recommended in flood risk analysis as it can be readily obtained from time-series data ${ }^{(33)}$. Limitations of this approach include that bias may be introduced due to the potential to exclude events that may not be the largest annually but could still be extreme, particularly important given that multiple extreme precipitation events could occur per year, and conversely it can also include less extreme events in particularly dry years. Madsen et al., ${ }^{(34)}$ compare and highlight benefits of the alternative Peak-Over-Threshold (POT) approach which will capture all events over a predetermined threshold. However, this method also has limitations and is used less frequently, chiefly as defining the threshold value is non-trivial. This can be based on judgment and expertise but there is no single threshold choice technique that has been shown to work well in all applications ${ }^{(35)}$. Using a larger amount of data has been suggested to improve rainfall frequency estimates ${ }^{(36)}$, and as such the method employed here is likely to benefit from the use of the $100 * 30$-year precipitation times-series data. 
Extreme Value Analysis (EVA) is used to calculate the return levels for each return period. The Generalised Extreme Value (GEV) distribution function is fitted to the AMS. EVA allows the probability and return levels of extreme events to be determined, for return periods exceeding that of the original data series, and even if events are more extreme than exists in the data series ${ }^{(37)}$. For each return period the GEV distribution allows the equivalent return level to be determined for each grid cell. These data provide the precipitation thresholds above which surface water flooding of a given return period is assumed to occur in the hourly baseline data, and for each grid cell. To understand the effect of climate change on risk the baseline precipitation thresholds are also applied to data for the 2030 s and 2050 s to calculate the change in frequency of events of given magnitude.

\subsection{Synthetic Flood Events}

In order to summarise the flood events, a daily event is defined here as any day when precipitation thresholds are surpassed in one or more grid cells in the study area for one hour or more. Whilst the common approach for meso-scale assessments has been based on the assumption of a spatially uniform return period, this approach follows other studies (e.g. ${ }^{(38,39)}$ ) by generating a set of synthetic flood events with spatially heterogeneous return periods ${ }^{(2)}$. Thus, for each rainfall event identified the spatial extent can be mapped and the corresponding flood depth for each return period ascertained from the equivalent surface water flood depth maps.

The surface water flood depth maps were generated under the Drain London project ${ }^{(40)}$ established to help predict and manage surface water flood risk, improve knowledge of the surface water drainage system and areas at most risk of flooding and look at options to reduce future risk. The maps were based on modelling a virtual representation of the ground 
topography and then applying water to the surface using a computational algorithm to determine the direction, depth and velocity of the resulting flows.

In summary, a linked 1D-2D hydraulic model of Greater London Boroughs was constructed using TUFLOW (Two-Dimensional Unsteady Flow) software. Underlying sewer network and road gullies were represented in 1D and overland flow in 2D. Key structures such as large culverts and road underpasses were also identified and included in the hydraulic model, although it is noted that the mapping of more detailed structures was still crude in places given the spatial resolution of data sources used ${ }^{(40)}$. The simulation modelling included flooding from run-off generation, sewers, drains, groundwater, small watercourses, and ditches which occurs as a result of heavy rainfall. The maps were generated by imposing rainfall events of known probability directly on the ground surface. No rainfall is applied directly onto building footprints as a second layer accounts for rainfall onto roofs, which is then distributed to represent the routing of rainfall into the network through gutters and drainpipes. This approach also provides a better representation of flooding in urban areas with a large number of basements, as rainfall is not applied directly into basements and basement flooding can only occur due to surface water that enters as overland flow if gutter or drainpipe capacity and/or the receiving sub-surface drainage network capacity is exceeded (full modelling details are included within London Borough Surface Water Management Plans e.g. see $\left.{ }^{(41)}\right)$.

The maps of surface water flood depth and extent were generated at a fine spatial resolution (5 $x 5 \mathrm{~m})$. The flood depth maps were used to estimate economic damage to residential properties within each grid cell (see section 3.3 below), and allowed total economic damage to be estimated for each synthetic spatially explicit surface water flood event. If the same grid cell is affected for two or more hours during a single day only the maximum hourly damage is used in the estimate. 


\subsection{Flood Damage Estimation}

Flood damage is considered to occur where flood depths exceed $0.1 \mathrm{~m}$ as this is the depth where the significant onset of impacts, e.g. damage to property, is considered to transpire (22). This study uses the UK Buildings residential building class dataset ${ }^{3}$ which provides the spatial footprint of properties, property type, and age for Greater London. This study does not consider scenarios of future change in the number, spatial pattern or economic value of residential buildings.

By overlaying the spatial flood maps onto the building data it is possible to identify which properties are at risk of surface water flooding, and the flood depth. The use of damage functions are widely used as a simplified method for estimating damage related to a particular hazard factor (in this case depth). While other more sophisticated multi-parameter model approaches have emerged these have tended to be for localised studies, and not easily transferred to broader urban areas as is the focus of this paper ${ }^{(42)}$.

The study utilises damage functions provided in the Multi-Coloured Manual (MCM), for short $(<12 \mathrm{hr})$ duration floods ${ }^{(22)}$. These, as with other, depth-damage functions have limitations due to uncertainty in the underlying data and assumptions which preclude their creation. For example, the depth-damage functions used by this study are comprised of synthetic data and not directly derived from analysis of historical flood events (ibid.). As they are based on national average data they are likely to underestimate losses for Greater London. Secondly, they can ignore the influence of other factors than depth on flood damage, such as velocity, duration, rise rate, and time of occurrence ${ }^{(43)}$. However, water depth is considered the single most important

\footnotetext{
${ }^{3}$ The Geolnformation group data $®$ copyright by The Geolnformation $®$ Group, 2014 Licence No. 3786.
} 
factor for building damage ${ }^{(44,43)}$ and so is a good characteristic to use. Damage to residential building fabric and contents are estimated for each affected property based on type (detached; semi-detached; terraced; flat), and age (unknown; pre-1919; 1919-1944; 1945-64; 1965-79; 1980-current).

\section{RESULTS}

\subsection{Rainfall Event Frequency}

The WG has been well validated against observed daily data from 1961-1990, including its performance in reproducing key rainfall statistics. Mean values and the 10th and 90th percentile uncertainty bounds are estimated from repeated realisations of the WG. Results for Heathrow (which lies within the study area) show that only in one instance (skewness of daily rainfall in May) do the observed statistics lie outside the modelled bounds ${ }^{(27)}$. Similarly, the performance of the WG in generating hourly time series is assessed by comparison with observed statistics used in fitting the model, as well as extremes. This has been carried out for 17 sites where data were available (including Heathrow). Due to the relatively short observed records of hourly data the uncertainty of the estimates shown in Fig. 3 are quite large.

It should be noted that the UKCP09 projections provide information on future climate change at the daily (not hourly) level. For this reason, the WG simulates future hourly rainfall by applying daily level change factors, and then using relationships between hourly and daily rainfall statistics derived from observed rainfall data to parametrise a stochastic model for hourly rainfall. These rules reflect the current climate and are fixed for future time periods so that new types of hourly weather behaviour, such as more intense thunderstorms, will not be explicitly reproduced by the WG for future periods. This is one limitation of the WG approach, although definitive information on observed and predicted changes in sub-daily rainfall in the UK is not yet available from any climate models. Few significant increasing trends in observed hourly 
annual maxima are reported by Blenkinsop and Fowler ${ }^{(45)}$. Increases of around $10 \%$ in summer future hourly rainfall in the south of England are reported by Chan et al., ${ }^{(46)}$ but this estimate is based on limited lengths of climate model simulations.

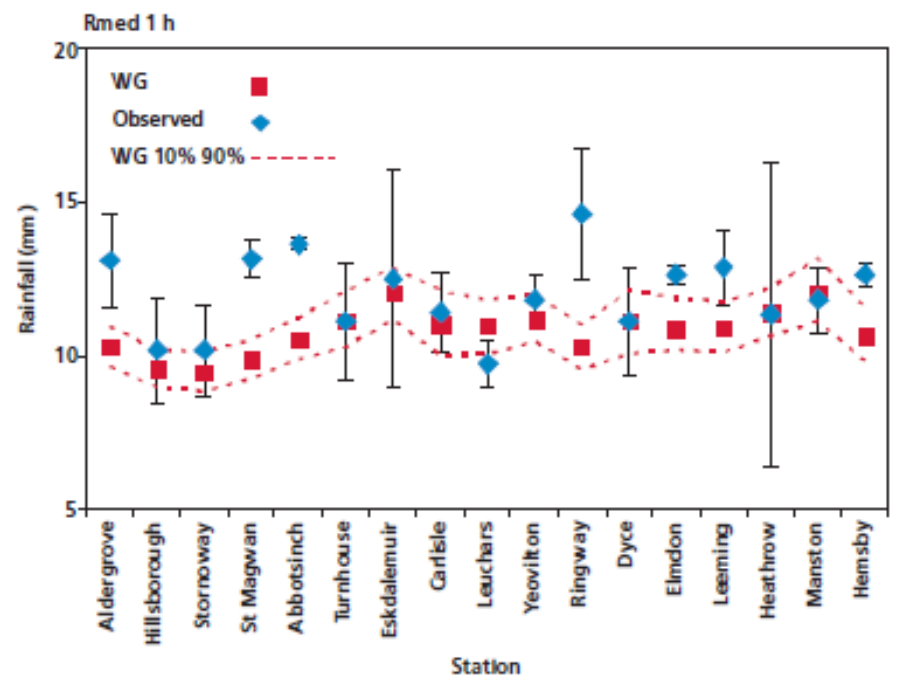

Fig. 3: Validation of 1 hour duration Rmed (median annual maximum rainfall) for 17 sites. WG results are the $10^{\text {th }}$ and $90^{\text {th }}$ percentile and mean of $10030 y r$ runs ${ }^{(27)}$.

EVA was used to calculate the return levels of hourly precipitation in the baseline data, for each return period and for each of the grid cells over the study area. The return levels, averaged across Greater London, ranged from $17.1 \mathrm{~mm}, 20.3 \mathrm{~mm}$, and $22.3 \mathrm{~mm}$ per hour for the $1 / 30 \mathrm{yr}$, 1/100yr, and 1/200yr return periods respectively. These data provide the thresholds above which extreme precipitation events (defined here as any day when these thresholds are exceeded in one or more grid cells in the study area for 1 hour or more) would be assumed to occur. Fig. 4 provides an illustration of two such events exceeding 1/30yr return levels in one or more cells of the model, highlighting their spatial extent and severity. 

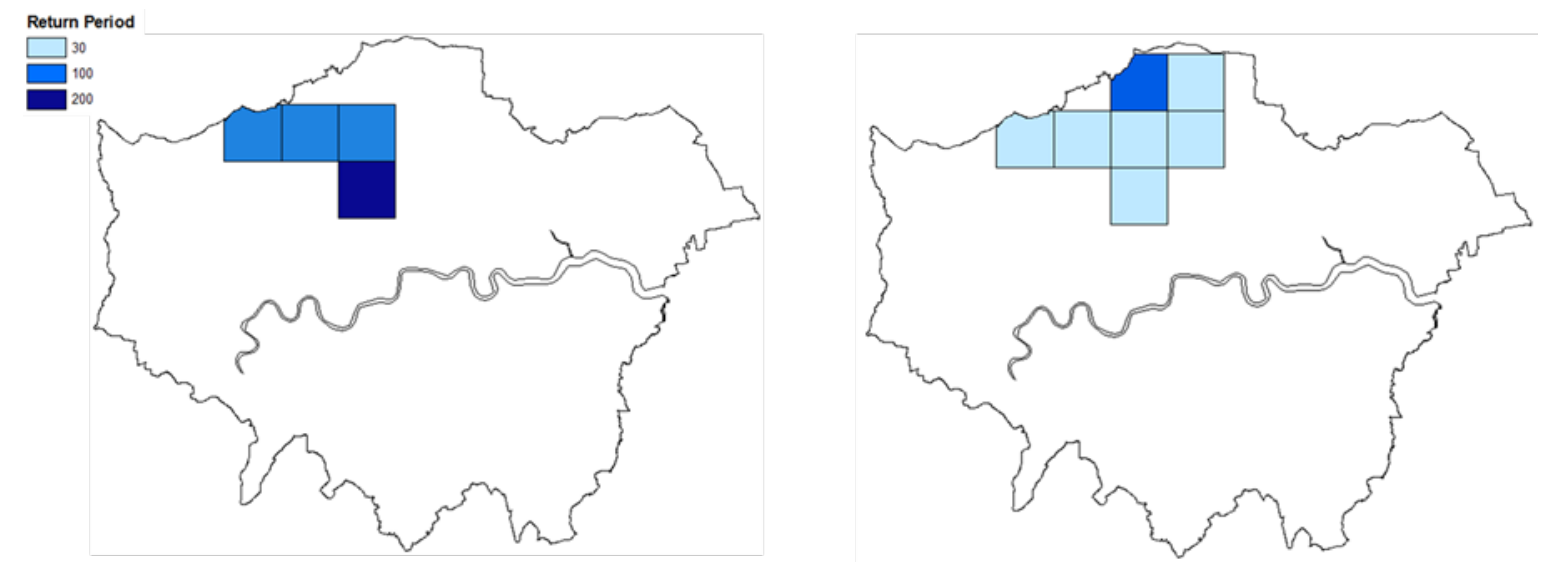

Fig. 4: Example outlines of two simulated daily extreme precipitation events over Greater London.

During the baseline period the average number of daily rainfall events per year exceeding the $1 / 30 \mathrm{yr}, 1 / 100 \mathrm{yr}$, or $1 / 200 \mathrm{yr}$ return levels in one or more cells of the model domain is $0.33,0.23$, and 0.03 respectively (Fig. 5). The frequency of rainfall events exceeding the present day $1 / 30 y r, 1 / 100 y r$, and $1 / 200 y r$ return levels increased by $165 \%, 64 \%$ and $600 \%$ under the $2030 \mathrm{H}$ scenario, and by $70 \%, 57 \%$, and $200 \%$ under the $2050 \mathrm{H}$ scenario. The range in results is indicated by the black lines indicating the10th and 90th percentiles. Although the thresholds for return levels were calculated across the entire time series data, this range reflects the difference seen across the 100 WG model runs. 


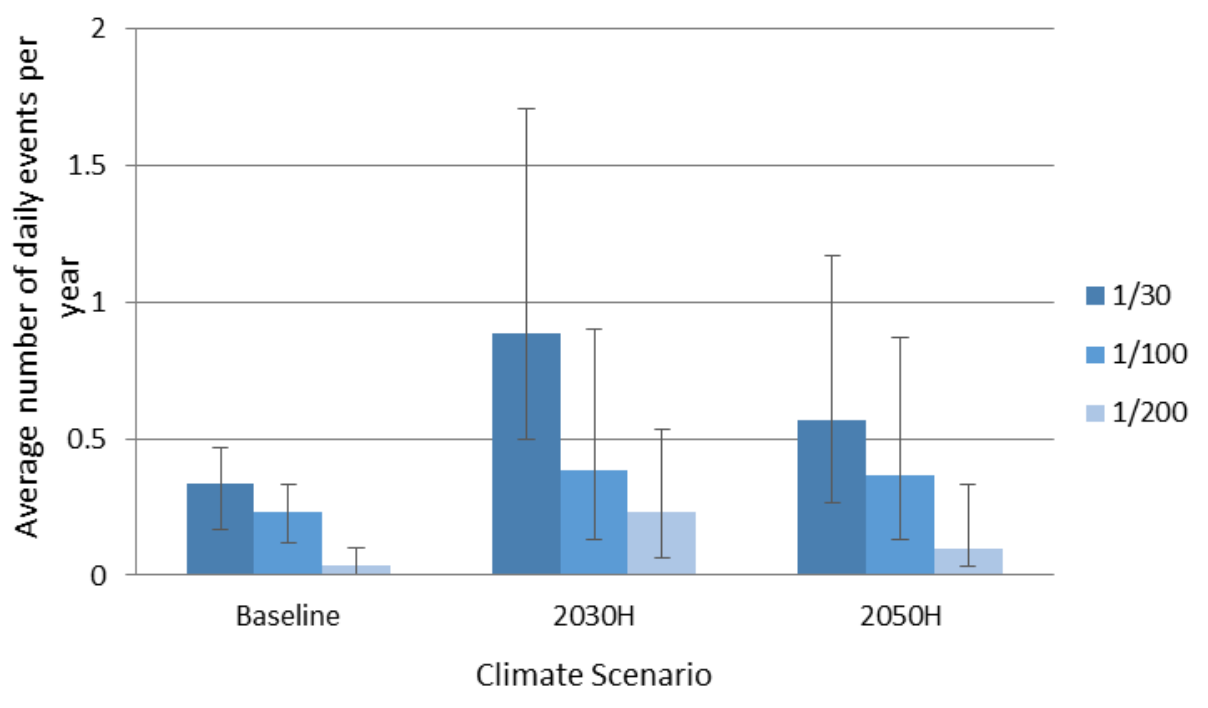

Fig. 5: A comparison of the average number of daily events per year calculated using the present day 1/30yr, 1/100yr, and 1/200yr return levels for each climate scenario.

Event frequency is higher in the 2030s than the 2050s. The relatively small change or reduction in frequency of events between the 2030s and 2050s is in line with other studies. For example, the study by Sanderson ${ }^{(37)}$ for London used UKCP09 data to illustrate that rainfall events are likely to become more frequent in the future, particularly between the present and 2040s. Sanderson postulated that this could be because the extreme rainfall events, especially those for the higher return periods (which have larger return levels) are already near to their maximum possible return levels. Although the atmosphere can hold more water vapour as it warms (the Clausius-Clapeyron relation), the incremental change in extreme rainfall events as the climate warms could become progressively smaller. This limit on the increase in extreme hourly rainfall is confirmed by Chan et al., ${ }^{(47)}$ who caution that that future extreme hourly precipitation intensities cannot simply be extrapolated from present-day temperature scaling. 


\subsection{Mapping Surface Water Flood Events}

For each extreme rainfall event identified each grid cell is linked, based on the return period, to the equivalent section of the Drain London flood depth maps to create synthetic surface water flood outlines (Fig. 6).
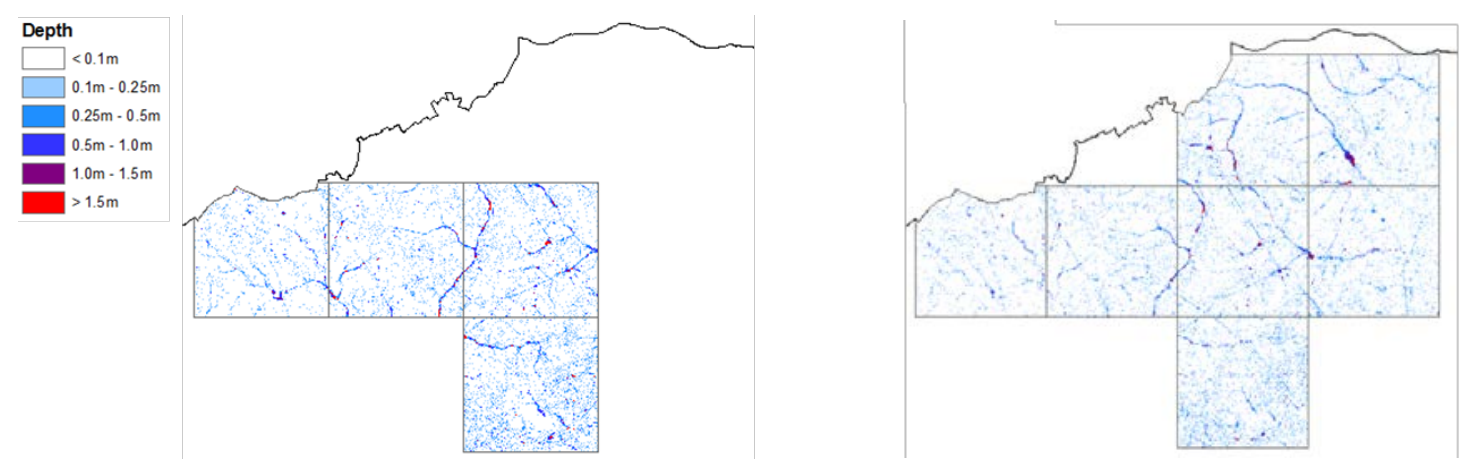

Fig. 6: Synthetic surface water flood outlines corresponding to the events shown in Fig. 4.

Based on the Drain London maps an area of Greater London of $40.12 \mathrm{~km}^{2}, 52.64 \mathrm{~km}^{2}$, and $59.17 \mathrm{~km}^{2}$ was estimated to be at risk of surface water flooding from a $1 / 30 \mathrm{yr}, 1 / 100 \mathrm{yr}$ and $1 / 200 y$ r return period event (equivalent to $2.6 \%, 3.3 \%$, and $3.8 \%$ of the total area of Greater London). During the baseline period the average area per event affected by surface water flooding exceeding the $1 / 30 \mathrm{yr}, 1 / 100 \mathrm{yr}$, or $1 / 200 \mathrm{yr}$ return levels was estimated to be $4.0 \mathrm{~km}^{2}$, $1.0 \mathrm{~km}^{2}$, and $0.9 \mathrm{~km}^{2}$ (Fig. 7). The smaller intensity events had a tendency to be broader in extent, while higher intensity events were shown to be more localised. The average area of $1 / 30 y$ r events decreased in the $2030 \mathrm{H}$ scenario suggesting a greater frequency of more localised events. The average area affected per event increased from the baseline in all other cases, and this increase was more significant for events exceeding the $1 / 100 \mathrm{yr}$ and $1 / 200 \mathrm{yr}$ return levels. Thus, while the frequency of these more intense events may be lower than seen for $1 / 30 y r$ events their average extent is likely to become more similar under future climate change, further increasing the economic risk of such events. 


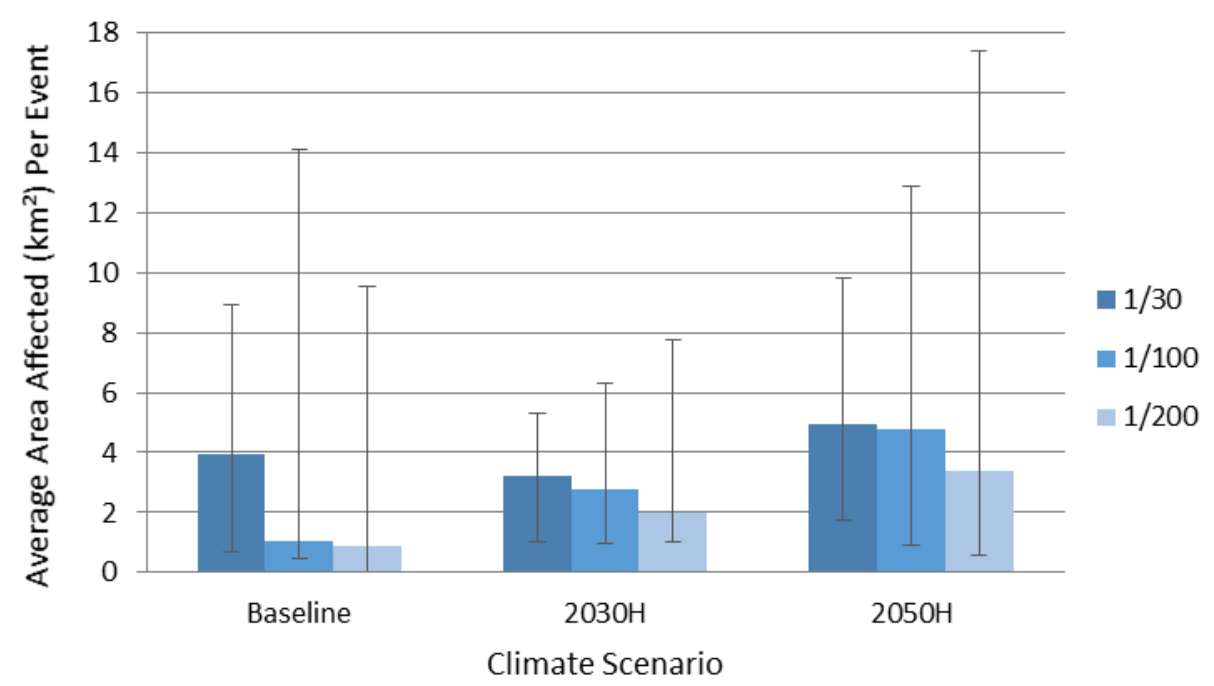

Fig. 7: A comparison of the average area affected $\left(\mathrm{km}^{2}\right)$ during surface water flood events calculated using the present day 1/30yr, 1/100yr, and 1/200yr return levels for each climate scenario.

Many studies adopt the approach of using a spatially uniform return period when mapping flood events, which can be unrealistic and lead to an overestimation of flood risk ${ }^{(23)}$. This method offers more sophistication in that it combines the flood depth data for three return periods with outputs from the weather generator. This enables extreme sampling of spatially heterogeneous rainfall events and corresponding flood depth and extent in a computationally efficient manner, and in a framework that can be used to approximate the consequences in terms of economic impacts.

However, limitations are that the maps are still only able to demonstrate consequences of the rainfall simulation on a $5 \times 5 \mathrm{~km}$ grid. This leads to rather artificial flood outlines as it does not provide a dynamic coupling between each grid cell and the synthetic maps assume flooding will end at the borders of the affected grid cells. Furthermore, it assumes that the flood depth and 
extent of heterogeneous rainfall over the study area will be the same as modelled under the Drain London scenarios of homogenous rainfall return periods (which, as noted above, are also likely to have been overestimated ${ }^{(23)}$ ).

\subsection{Surface Water Flood Risk}

To assess the potential scale of damage to residential properties from surface water flooding damages were firstly calculated across the whole of Greater London based on the Drain London flood depth maps and methodology outlined in section 3.3. Table I shows that 312,551 to 392,758 residential properties (approximately $9.5 \%$ to $12.0 \%$ of total residential properties in Greater London) were at some level of risk from surface water flooding. These figures are somewhat lower than higher end estimates from the Environment Committee that suggest that up to 680,000 properties in London are at risk from surface water flooding from a 1/200 year return period event ${ }^{(20)}$. These differences may reflect the use of the more detailed surface water flood depth maps from Drain London in this study, and the methodology used to calculate which properties would be susceptible to surface water flooding (discussed further below).

Assuming surface water flooding affected the whole of Greater London simultaneously resulted in economic damages to residential buildings of $£ 4.5$ to $£ 6.0$ billion for $1 / 30 \mathrm{yr}$ and $1 / 200 \mathrm{yr}$ flood events (Table I). As a comparison flood claims following the UK 2007 summer floods were estimated to be $£ 3.2 \mathrm{bn}$. Whilst the storms of summer 2007 were not primarily centred on London the enormity of the damage, disruption, and long recovery times that could occur given such an event are apparent. 


\begin{tabular}{ccccc}
\hline \multirow{2}{*}{$\begin{array}{c}\text { Return } \\
\text { period }\end{array}$} & $\begin{array}{c}\text { Dumber of } \\
\text { properties }\end{array}$ & $\begin{array}{c}\text { Damage to } \\
\text { building fabric } \\
\text { affected }\end{array}$ & $\begin{array}{c}\text { Damage to } \\
\text { building } \\
\text { contents }\end{array}$ & $\begin{array}{c}\text { Total damages } \\
\text { (£ million) }\end{array}$ \\
\hline $1 / 30 \mathrm{yr}$ & 312,551 & $£ 2,319$ & $£ 2,165$ & $£ 4,484$ \\
\hline $1 / 100 \mathrm{yr}$ & 352,942 & $£ 2,736$ & $£ 2,499$ & $£ 5,235$ \\
\hline $1 / 200 \mathrm{yr}$ & 392,758 & $£ 3,141$ & $£ 2,826$ & $£ 5,967$ \\
\hline
\end{tabular}

Table I: Estimated economic impact of surface water flooding on residential buildings in Greater

London

Fig. 8 shows these economic damages aggregated to a ward level for Greater London. The maps highlight the spatial pattern of risk based on the extent of surface water flooding and depth, as well as the concentration, number, and type of residential buildings affected in each ward. The figure highlights particular hotspots in Greater London, particularly in the South and South-East, where the risk of surface water flooding to residential properties could reach approximately $£ 50$ million.
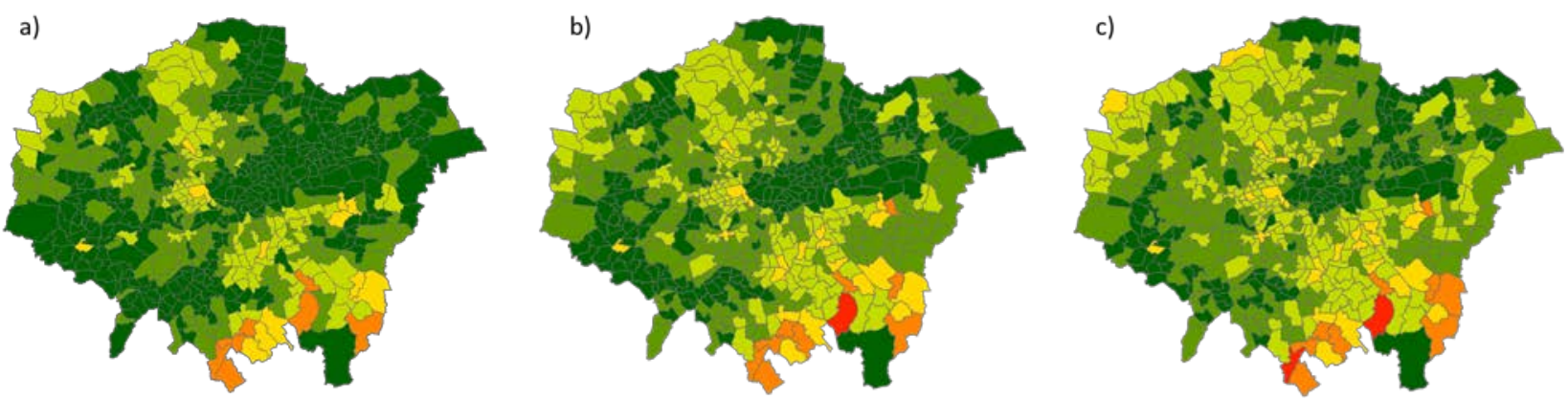

Damage (million £)

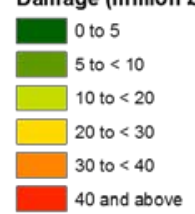


Figure 8: Economic damage to residential properties from surface water flooding, aggregated to a ward level for a) 1/30yr return period, b) 1/100yr return period, and c) 1/200yr return period

Secondly, damages were calculated for each synthetic flood event where one or more grid cells exceeded the 1/30yr return level. Based on the synthetic flood outlines (e.g. Fig. 6) economic damage to individual residential buildings were estimated using the flood depth data and depthdamage functions and summed for each grid cell. Damages were then summed for each event to provide an overall estimate of surface water flood damage (Fig. 9).

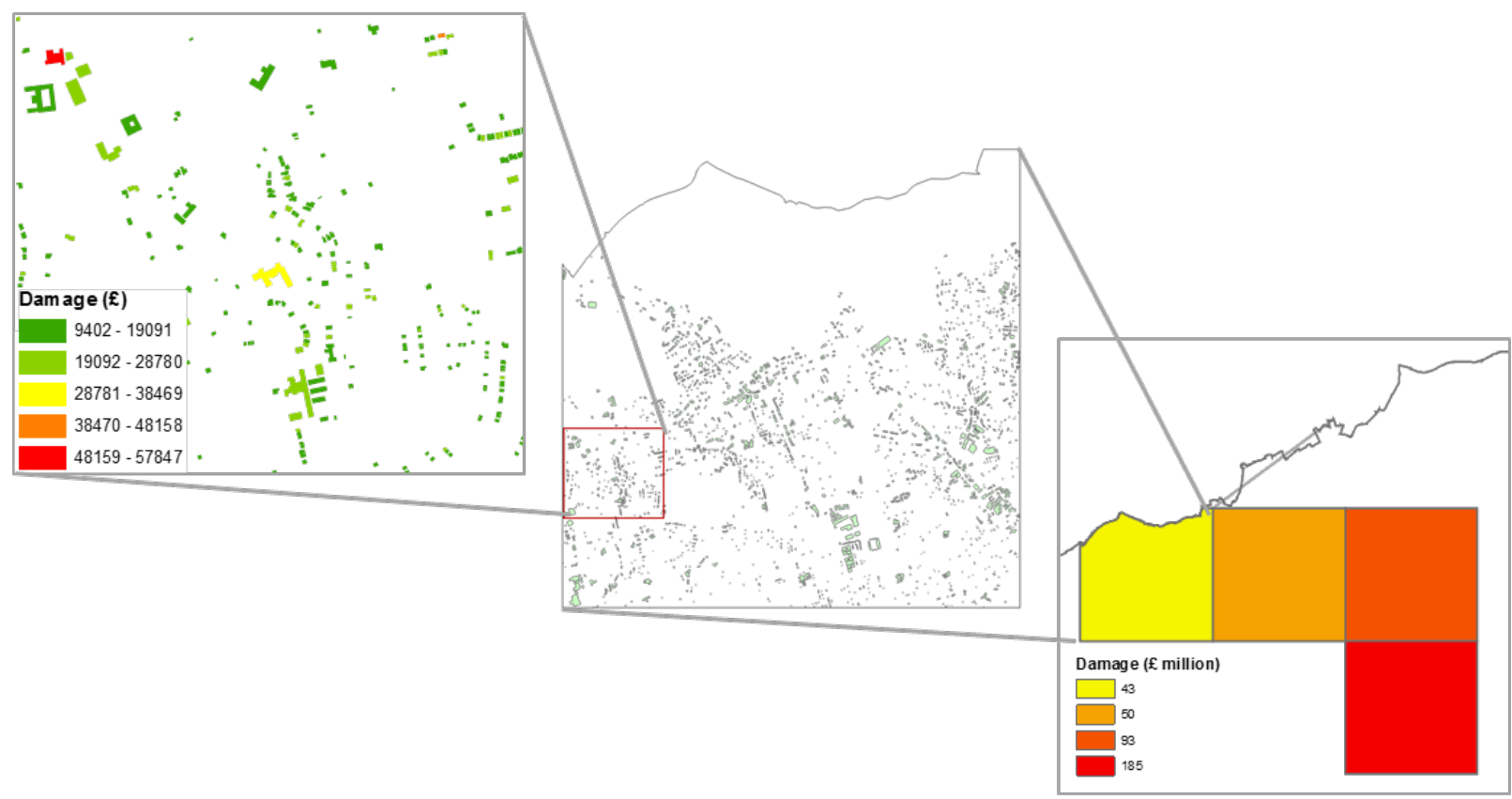

Fig. 9: Left panel: Estimated damage to a sub-set of residential properties at risk of flooding during a 1/100 yr event and the damage per property. Middle panel: Spatial footprint of all properties at risk in one grid cell based on the synthetic flood outline. Right panel: The total damage per grid cell for the event (corresponding to the flood outline shown in Fig.6).

Economic damage to residential properties was estimated for each surface water flood event detected, and summed to provide an estimate of annual damages for each of the $100 * 30$ year 
model runs. The overall risk from surface water flooding was estimated by i) calculating the probability that a certain level of annual damage will be exceeded, based on the annual frequency of events and their associated damage; ii) using this data to create annual exceedance probability-loss curves (Fig. 10); and iii) integrating the area under these curves to calculate the Expected Annual Damage (EAD).

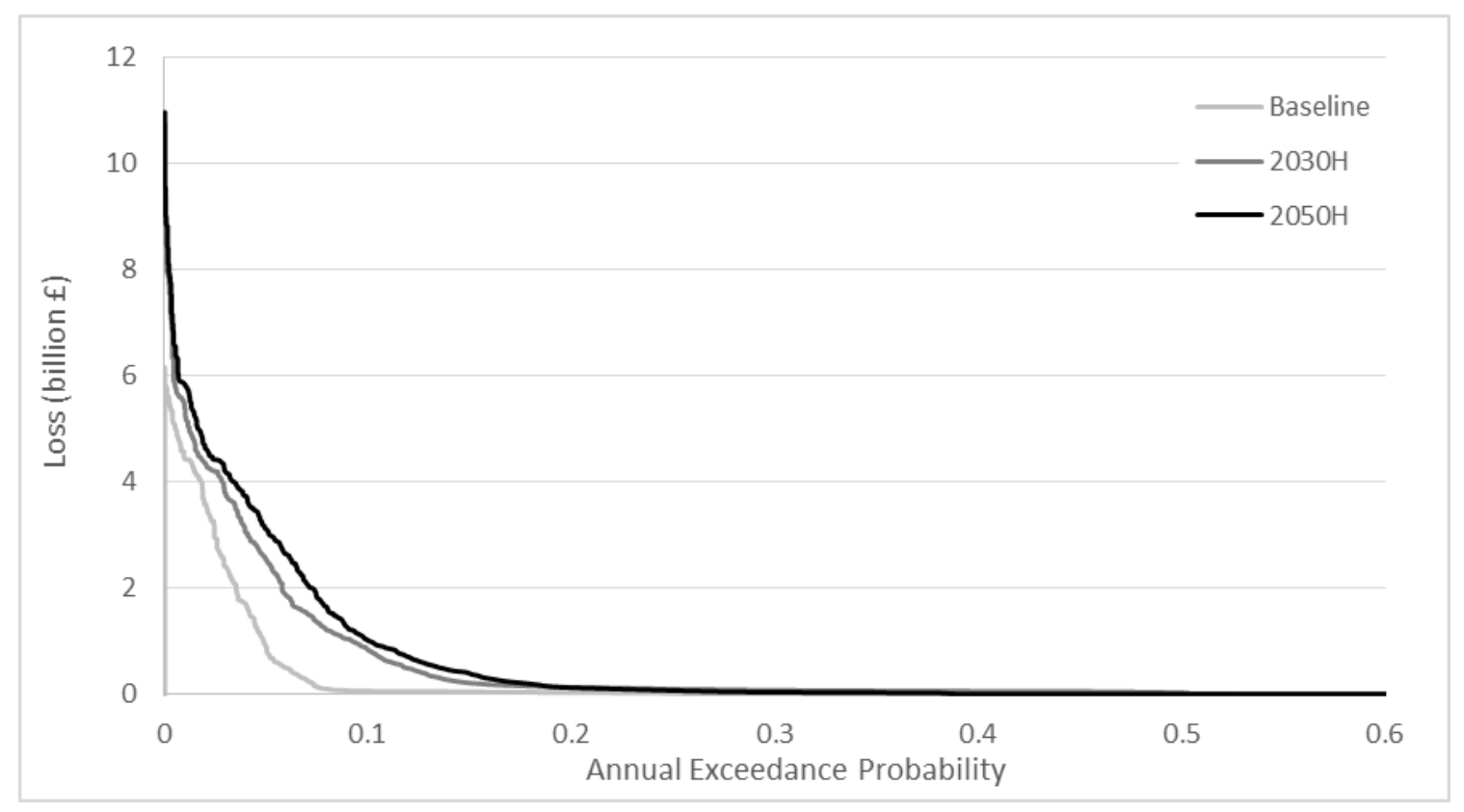

Fig. 10: Annual exceedance probability loss curves for Greater London

The EAD of surface water flooding in Greater London was estimated to be $£ 171$ million in the baseline scenario, increasing to $£ 343$ million and $£ 390$ million under the $2030 \mathrm{H}$ and $2050 \mathrm{H}$ climate scenarios. While event frequency was estimated to be slightly higher in the 2030s than the 2050s (section 4.1), the EAD from surface water flood events increased from the baseline by $101 \%$ and $128 \%$ under the $2030 \mathrm{H}$ and $2050 \mathrm{H}$ climate scenarios respectively, suggesting an increase in both the severity and extent of surface water flood events which do occur under the future climate scenarios. In comparison, Defra estimated flood damage from surface water runoff could increase by $60-220 \%$ over the next 50 years ${ }^{(14)}$. Half of this increase was linked to changing precipitation patterns due to climate change, and half linked to urbanisation. The 
results are comparative to those presented here given this study does not consider additional effects of urbanisation.

$\operatorname{Defra}^{(10)}$ estimated annual costs of surface water flooding in the UK to range between $£ 1$.3bn to $£ 2.2 \mathrm{bn}$, thus this study highlights the significant contribution to risk from Greater London alone. In contrast, the recent study by Sayers et al., ${ }^{(48)}$ presented much lower estimates for the present day costs of surface water flooding, estimating an EAD of $£ 200$ million for the whole of England. It is postulated that this is due to differences in the methodologies used. For example, Sayers et al., use a representative average damage figure for flooded property $(£ 11,000)$ which is then multiplied by the return period of the event and the number of properties affected to ascertain damages. In this study damages are linked to each affected property based on flood depth, building type and age, with potential damage to individual properties ranging between $£ 7,699$ and $£ 85,480$.

Secondly, the EAD is expected to be larger due to differences in methodologies for assessing the number of properties at risk of surface water flooding, as well as the different level of detail in the flood depth maps used. As indicted in Table I, 352,942 properties in Greater London were estimated to be at risk from 1/100 year surface water flooding. In comparison, Sayers et al., (35) estimated 430,000 properties in England would be at risk from 1/75 year surface water flooding. The approach here assumes all residential properties whose boundaries are intercepted by the flood maps are flooded. Whilst the methodological approach underlying the Drain London flood depth maps improved on the representation of urban infrastructure in the modelling, this remains coarse when considering detailed street geography such as curbs and walls, and uncertainty related to the direct coupling of this data onto GIS data of residential buildings, and subsequently the coarser WG data is difficult to quantify. 
A third important factor is the way that climate change is explicitly modelled in the analysis, using high spatial resolution probabilistic projections of hourly precipitation from a novel WG conditioned upon the UKCP09 probabilistic climate projections. In contrast within the Surface Water Management Plans (SWMPs), required for each of the London Boroughs (and other local authorities), climate change is taken into account by increasing rainfall intensity by $30 \%$ in the modelled results. Similarly, Sayers et al., ${ }^{(35)}$ also applies climate change uplift rates (ranging from $0-70 \%$ based on published studies) to ultimately estimate the future probability of present day run-off values and scale the present day impacts to account for climate change. In justifying such uplift rates Defra ${ }^{(10)}$ report that there is no standardised methodology for determining the impact that climate change will have on surface water flooding. However, besides limitations of focusing on a single climate response, using a fixed uplift rate does not facilitate the quantification of uncertainties for Governments and policy makers to help support the design and implementation of robust and economical adaptation options.

Given underlying uncertainties related to the methodologies underlying the various components of the analysis (e.g. from the spatial urban WG, use of depth-damage functions, and the scale and process by which the Drain London surface water flood depth maps are generated), and the methodological approach to link this data in this analysis, the results presented here could be viewed as an upper bound on the potential number of properties at risk and related economic damages from surface water flooding in Greater London.

Conversely, the results presented could also be considered conservative in broader terms in that flood risk is based on estimates of direct damage only, excluding indirect costs but also implications of additional contamination from water, and any adaptive measures in place. For example, it is reported that flood incidents can be accompanied by significant emergency costs such as additional expenditure due to increased demand for police, fire and ambulance 
services. It has been estimated that these are equivalent to $10.7 \%$ of property damages in the UK ${ }^{(22)}$. Some multi-parameter models have begun to incorporate such factors in estimates, although the prediction of these remains difficult ${ }^{(2)}$.

\section{CONCLUSIONS}

This study presents a framework for evaluating the current and future risk of surface water flooding in Greater London, by linking high spatial resolution probabilistic projections of hourly precipitation and detailed surface water flood depth maps. The method supports a meso-scale risk analysis, allowing investigation of the potential implications of climate change as well as the identification of risk 'hot spots' across Greater London. The study highlights significant increases in surface water flood risk under climate change, assuming no additional adaptation options are included. This echoes broader concerns that that EAD from flooding will increase significantly by the 2080s if current levels of adaptation remain static ${ }^{(48)}$.

While it has been applied to a case study of Greater London the method is transferable (dependent on availability of relevant data) and could be extended to other areas in the UK. Given the localised nature of surface water flood events a key advantage of this methodology is that specific spatially heterogeneous events can be identified and quantified, whilst explicitly considering the modelled effects of climate change on precipitation regimes. As discussed, this progresses other methods employed, for example accounting for the impact of climate change by applying an uplift rate to rainfall intensity and depth ${ }^{(10)}$. Similarly, this study builds upon such assessments by utilising detailed surface water flood depth maps and a spatially explicit residential property database. As well as providing an overall assessment of the potential cost of surface water flooding, the probabilistic approach allows estimates of risk and uncertainty to be made. 
Further advantages include the flexibility of the approach to support the evaluation of effects of different flood risk management measures and polices. For example, adaptation pathways have been developed to explore the effectiveness of varying levels of PLPMs and Sustainable Drainage Systems (SUDS) in reducing flood risk in Greater London. This reflects the direct effect of property protection measures on estimates of damage to property, and the effect of SUDS, through a modelled change in permeable green space and rainfall runoff, on the Drain London flood depth maps ${ }^{(49)}$. A second application has been the assessment of these adaptation measures to explore how risk reduction could be achieved by different actors and the role of flood insurance, in the context of climate change ${ }^{(50)}$.

Yet, the approach is not without limitations and as with any assessment of surface water flood risk there is significant uncertainty underlying the model components and their integration, with results very difficult to validate against historical flood events. Future advances, whilst computationally more expensive, could be made by fully integrating the spatial WG with the surface water flood model to provide a dynamic approach to modelling surface water flood extent and depth of spatially heterogeneous events. Such an approach has already been applied by Falter et al., (23) for fluvial flooding in the Mulde Catchment in Germany, with results generated at a resolution of $100 \mathrm{~m}$.

As such, there are clear advantages of continued research in this area. It is hoped that such probabilistic information will be useful for governments and policy makers as they prepare for future climate risks, and begins to address the need for the quantification of surface water flood risk and information to support adaptation options ${ }^{(51)}$. 


\section{ACKNOWLEDGEMENTS}

This paper has benefited from research undertaken as part of the ARCADIA Project (Adaptation and Resilience in Cities: Analysis and Decisions-making using Integrated Assessment), funded by the Engineering and Physical Sciences Research Council, award number EP/G060983/1.

The authors would also like to acknowledge support from the Greater London Authority (GLA), who provided access to the Drain London surface water flood depth maps through their engagement with the ARCADIA project.

\section{REFERENCES}

1. EM-DAT. Em-dat: The cred/ofda international disaster database 2016.

2. de Moel H, Jongman B, Kreibich $\mathrm{H}$ et al. Flood risk assessments at different spatial scales. Mitigation and Adaptation Strategies for Global Change, 2015; 20 (6):865-90.

3. Falconer $\mathrm{RH}$, Cobby D, Smyth $\mathrm{P}$ et al. Pluvial flooding: New approaches in flood warning, mapping and risk management. Journal of Flood Risk Management, 2009; 2 (3):198-208.

4. European Water Association. EWA expert meeting on pluvial flooding in Europe. Brussels, Belgium: EWA, 28 October 2009.

5. Blanc J, Hall JW, Roche $\mathrm{N}$ et al. Enhanced efficiency of pluvial flood risk estimation in urban areas using spatial-temporal rainfall simulations. Journal of Flood Risk Management, 2012; 5:143-52.

6. Hall J, Sayers P, Dawson R. National-scale assessment of current and future flood risk in england and wales. Natural Hazards, 2005; 36 (1-2):147-64.

7. Pitt M. Learning lessons from the 2007 floods. London: Cabinet Office.

8. Environment Agency. Review of 2007 summer floods. In., Series Review of 2007 summer floods. Bristol: Environment Agency; 2007; p. 33. 
9. House of Commons. Winter floods 2015-16. Briefing paper number cbp7427. London: House of Commons; 2016.

10. Defra. Commencement of the flood and water management act 2010, schedule 3 for sustainable drainage: Impact assessment. London: Defra; 2011; p. 42.

11. IPCC. Summary for policymakers. Climate change 2013: The physical science basis. Contribution of working group i to the fifth assessment report of the intergovernmental panel on climate change Cambridge, United Kingdom and New York, NY, USA.: Cambridge University Press; 2013. 29 p. (TF Stocker, D. Qin, G.-K. Plattner, M. Tignor, S.K. Allen, J. Boschung, A. Nauels, Y. Xia, V. Bex and P.M. Midgley. editor).

12. Fowler HJ, Ekström M. Multi-model ensemble estimates of climate change impacts on uk seasonal precipitation extremes. International journal of climatology, 2009; 29 (3):385-416.

13. Ramsbottom D, Sayers $P$, Panzeri M. Climate change risk assessment for the floods and coastal erosion sector. UK climate change risk assessment. London: Defra.

14. Adaptation Sub-Committee. Climate change - is the UK preparing for flooding and water scarcity? London: Committee on Climate Change.

15. Houston D, Werritty A, Bassett D et al. Pluvial (rain-related) flooding in urban areas: The invisible hazardJoseph Rowntree Foundation, November 2011.

16. ONS. Census: Standard area statistics (england and wales). University of Manchester: Mimas.

17. Greater London Authority. Land area and population density, ward and borough. London: Greater London Authourity, Sep 2015.

18. Greater London Authority. The Iondon climate change adaptation strategy. London: Greater London Authority, 27 October, 2011.

19. Greater London Authority. Flood risks in London: Summary of findings 2014. London: GLA.

20. Environment Committee. For a rainy day. The mayor's role in managing london's flood risk in case of severe rainfall. London: Greater London Authority, July 2011. 
21. HR Wallingford. Development of spatial indicators to monitor changes in exposure and vulnerability to flooding and the uptake of adaptation actions to manage flood risk in england: Results 2012. Oxfordshire: HR Wallingford Ltd, August 2012.

22. Penning-Rowsell E, Viavattene $\mathrm{C}$, Pardoe $\mathrm{J}$ et al. The benefits of flood and coastal risk management: A handbook of assessment techniques. London: Flood Hazard Research Centre.

23. Falter D, Schröter K, Dung NV et al. Spatially coherent flood risk assessment based on long-term continuous simulation with a coupled model chain. Journal of Hydrology, 2015; 524:182-93.

24. Burton A, Kilsby CG, Fowler $\mathrm{HJ}$ et al. Rainsim: A spatial-temporal stochastic rainfall modelling system. Environmental Modelling \& Software, 2008; 23 (12):1356-69.

25. Burton A, Glenis V, Jones MR et al. Models of daily rainfall cross-correlation for the united kingdom. Environmental Modelling \& Software, 2013; 49:22-33.

26. Burton A, Fowler $\mathrm{HJ}$, Blenkinsop $\mathrm{S}$ et al. Downscaling transient climate change using a neyman-scott rectangular pulses stochastic rainfall model. Journal of Hydrology, 2010; 381 $(1-2): 18-32$.

27. Jones PD, Kilsby CG, Harpham C et al. Uk climate projections science report: Projections of future daily climate for the uk from the weather generator. University of Newcastle, UK.

28. Tomlinson JE, Mcsweeney RT, Darch GJC et al. Briefing: Wrapt - software for analysing ukcp09 weather generator output. Proceedings of the Institution of Civil Engineers: Water Management, 2014; 167 (6):318-21.

29. Murphy JM, Sexton DMH, Jenkins GJ et al. UK climate projections science report: Climate change projections. Met Office Hadley Centre, Exeter, UK, June 2009.

30. Kilsby CG, Jones PD, Burton A et al. A daily weather generator for use in climate change studies. Environmental Modelling \& Software, 2007; 22 (12):1705-19. 
31. Fowler $\mathrm{HJ}$, Ekström M, Kilsby CG et al. New estimates of future changes in extreme rainfall across the UK using regional climate model integrations. 1. Assessment of control climate. Journal of Hydrology, 2005; 300 (1-4):212-33.

32. Moss RH, Edmonds JA, Hibbard KA et al. The next generation of scenarios for climate change research and assessment. Nature, 2010; (463):747-56.

33. Faulkner D. Rainfall frequency estimation. Vol. 2, flood estimation handbook: NERC Centre for Ecology and Hydrology; 1999. 110 p.

34. Madsen H, Rasmussen PF, Rosbjerg D. Comparison of annual maximum series and partial duration series methods for modeling extreme hydrologic events: 1. At-site modeling. Water Resources Research, 1997; 33 (4):747-57.

35. Roth M, Jongbloed G, Buishand TA. Threshold selection for regional peaks-over-threshold data. Journal of Applied Statistics, 2016; 43 (7):1291-309.

36. Svensson C, Jones DA. Review of rainfall frequency estimation methods. Journal of Flood Risk Management, 2010; 3 (4):296-313.

37. Sanderson M. Changes in the frequency of extreme rainfall events for selected towns and cities. Exeter: Met Office.

38. Rodda HJE. The development and application of a flood risk model for the czech republic. Natural Hazards, 2005; 36 (1):207-20.

39. Falter D, Dung NV, Vorogushyn S et al. Continuous, large-scale simulation model for flood risk assessments: Proof-of-concept. Journal of Flood Risk Management, 2016; 9 (1):3-21.

40. Greater London Authority. London sustainable drainage action plan. London: Greater London Authority.

41. The Royal Borough of Kensington and Chelsea. Surface water management plan appendix b - modelling details. Avaliable at: Https://www.Rbkc.Gov.Uk/wamdocs/rbkc appendix b modelling details v4.Pdf, January 2014. 
42. Domeneghetti A, Carisi F, Castellarin A et al. Evolution of flood risk over large areas: Quantitative assessment for the po river. Journal of Hydrology, 2015; 527:809-23.

43. Messner F, Penning-Rowsell E, Green C et al. Evaluating flood damages: Guidance and recommendations on principles and methodsHR Wallingford, UK January 2007

44. Elmer F, Thieken AH, Pech I et al. Influence of flood frequency on residential building losses. Nat. Hazards Earth Syst. Sci.,, 2010; 10:2145-59.

45. Blenkinsop S, Fowler HJ. An hourly and multi-hourly extreme precipitation climatology for the UK and long-term changes in extremes. In Vulnerability, Uncertainty, and Risk: Quantification, Mitigation, and Management - Proceedings of the 2nd International Conference on Vulnerability and Risk Analysis and Management, ICVRAM 2014 and the 6th International Symposium on Uncertainty Modeling and Analysis. ISUMA 2014; 2014. 1385-94 p.

46. Chan SC, Kendon EJ, Fowler HJ et al. Projected increases in summer and winter UK subdaily precipitation extremes from high-resolution regional climate models. Environmental Research Letters, 2014; 9 (8).

47. Chan SC, Kendon EJ, Roberts NM et al. Downturn in scaling of UK extreme rainfall with temperature for future hottest days. Nature Geoscience, 2016; 9 (1):24-8.

48. Sayers PB, Horritt M, Penning-Rowsell E et al. Climate change risk assessment 2017: Projections of future flood risk in the UK. Research undertaken by sayers and partners on behalf of the committee on climate change. London: Committee on Climate Change.

49. Kingsborough A, Jenkins K, Hall JW et al. Urban adaptation pathways: Demonstration of an integrated approach in london. Urban Climate, 2016; In review.

50. Jenkins K, Surminski S, Hall JW et al. Assessing surface water flood risk and management strategies under future climate change: Insights from an Agent-Based Model. Science of The Total Environment, 2017; 595, 159-168. 
51. Greater London Authority. The Iondon plan: Spatial development strategy for greater Iondon. In., Series The Iondon plan: Spatial development strategy for greater london. London: Greater London Authority; 2011. 